\title{
Structural Modeling in Marketing: Review and Assessment
}

\author{
Pradeep Chintagunta \\ Graduate School of Business, University of Chicago, \\ 1101 E 58th St, Chicago IL 60637, pradeep.chintagunta@ChicagoGsb.edu \\ Tülin Erdem \\ Haas School of Business, University of California, Berkeley, \\ Berkeley, CA 94720-1900, erdem@,haas.berkeley.edu \\ Peter Rossi \\ Graduate School of Business, University of Chicago, \\ 1101 E 58th St, Chicago IL 60637, peter.rossi@ChicagoGsb.edu \\ Michel Wedel \\ Ross School of Business at the University of Michigan \\ 701 Tappan Street, Ann Arbor, MI 48109-1234, wedel@,umich.edu
}

May 2005 


\title{
Structural Modeling in Marketing: Review and Assessment
}

\begin{abstract}
The recent marketing literature reflects a growing interest in structural models, stemming from: 1) the desire to test a variety of behavioral theories with market data, and 2) recent developments that facilitate estimation of and inference for these models. Whether one should always go through the effort of developing such tightly parameterized models with the associated computational burden of estimating them, and whether it pays off to make strict behavioral assumptions in terms of better decisions, remain open questions. To shed some light on these issues, we provide examples of structural approaches to consumer choice and demand as well as examples where the goal is to study the nature of competition in the marketplace. From that review spawns our discussion of issues in the development and application of structural models, including their estimation, testing and validation, their applicability in the practice of marketing, and their usefulness for normative, as well as descriptive purposes.
\end{abstract}




\section{Introduction}

The recent marketing literature reflects a growing interest in structural models. By structural models we mean those that rely on economic and/or marketing theories of consumer or firm behavior to derive the econometric specification that can be taken to data. In particular, structural models are typically derived based on optimizing behavior of agents (e.g., utility maximizing by consumers, profit maximizing by firms, etc.). Further, as one can assess the role of the behavioral assumptions in driving empirical findings, the appropriateness of these assumptions can be investigated. Consequently, the structural approach allows us to test the theories from which the models are derived, and obtain behavioral predictions that are invariant to the effects of policy changes. Hence, the increased interest in the development and application of structural models in marketing stems from: 1) the desire to test a variety of behavioral theories with market data, and 2) recent developments that facilitate estimation of and inference for these models.

Although it is clear that there are situations where a structural approach may be preferred by marketing researchers, whether structural modeling will become the dominant paradigm in marketing, whether one should always go through the effort of developing such tightly parameterized models with the associated computational burden of estimating them, and whether it pays off to make strict behavioral assumptions in terms of better decisions, remain open questions. Our objective in this paper is to shed some light on these issues. For this, we first provide examples of structural approaches to consumer choice and demand - both static and dynamic -- as well as to the nature of competition in the marketplace. From that review spawns our discussion of several important issues in the development and application of structural models, including their estimation, testing and validation, their applicability in the practice of marketing, and their usefulness for normative, as well as descriptive purposes. Interested readers are also referred to related reviews by 
Kadiyali, Sudhir and Rao (2000), Dube, Hitsch and Manchanda (2002) and Chintagunta, Kadyali and Vilcassim (2004).

We aim to provide a critical assessment of our views of the strengths and weaknesses of structural modeling and its future, in marketing. There are two factors that can facilitate more widespread application of structural models in marketing in particular. The first is the availability of stated and revealed preference data at unprecedented levels of disaggregation (right up to the individual consumer or household). Second, residing at the intersection of applied economics and psychology, marketing is in a unique position to develop new structural models which incorporate behavioral theory from both economics and psychology. Given the richness of data in marketing, more realistic and, hopefully, more powerful theories of consumer and firm behavior can be developed and tested.

\section{Structural and Reduced-Form Models}

The goals of econometric modeling are to explain past behavior of agents' and to predict their future behavior. However, the relative weights placed on data-fitting (which is easier, ceteris paribus, the less structure is imposed on data) versus relying on theory in building an econometric model has been the topic of much debate. Whereas proponents of "reduced-form" models prioritize fit to the empirical data and propose flexible functional forms to reflect variations in the data and let the data "speak," those of structural models prioritize theory as a guiding source for the empirical specification. Haavelmo (1944) and Lucas (1976) provide arguments for the use of structural

\footnotetext{
${ }^{1}$ We should note that there are at least two meanings of reduced form. The classical meaning is that one uses a fully specified theoretical model to derive specific predictions for data relationships. Data are then analyzed to see if they fit those relationships, without reference to the full model or system. A more recent, and somewhat more colloquial, use of the term is to refer to an approach under which one fits a statistical model to data without first developing an underlying theoretical model (a data-driven approach) (Erdem et. al. 2005). We will loosely refer to both using "reduced form model", although a better term may be statistical/econometric model.
} 
econometric models in economics that have been derived from, or at least are consistent with, an underlying economic theory. They argue that structural models can be used to predict the effects of a shift to a policy regime which is different from that observed in the historical data.

Reduced-form models in general aim at representing consumers' or firms' historical decision rules as derived from available marketing data. The resulting estimates are used to predict the behavior of these agents in the future. Predictive validation of (reduced form) models in hold-out data has received much attention in the marketing literature. Here, by hold-out data we mean time series observations from the agents that were used in calibrating the model. Assessing predictive validity on such hold-out data has become the standard for both comparing the predictive power of new versus old models as well as for assessing their validity and robustness. But, it is important to realize that a reduced form model may have excellent predictive validity (particularly if assessed on hold-out samples of consumers) and still provide misleading predictions of the effects of (marketing) strategy changes, if the impacts of such changes are too far from the historical data. In order for a model to be useful for predicting strategy changes, ideally there must be a similar change in the relevant strategy variables in the data.

Thus, reduced form models run the risk of producing misleading forecasts of the effects of strategy changes that change the stochastic context in which decisions are made. This arises when a strategy change affects the agents' decision rules themselves, i.e. the parameters of the decision model or even its functional form. Historical marketing data may not display sufficient variability in strategy regimes to reliably estimate the effect of strategy changes on the parameters representing the agents' decision process. Structural models seek to parameterize the way in which the stochastic decision context created by policies affects the agents' preferences and decision rules (Rust 1994). But, whereas in economics, policy changes mostly constitute changes in the economic environment, (for example, privatization, de-regulation) or a change in the nature of the strategic interaction of 
agents (for example, price setting or taking, or competitive versus collusive behavior), in marketing strategy changes of interest, next to the last mentioned strategic interactions, often constitute of changes in the behavior of a particular agent (a change in promotional strategy of the firm), which have a more limited impact on the economic system. In many cases structural parameterizations are derived from the economic assumption of "optimality" of behavior of agents and the market equilibrium paradigm. This often involves assuming that, given the information available to them, consumers and firms are rational expected-utility maximizing entities, which allows optimal behavioral specifications to be derived that are applicable under a wider variety of decision contexts and economic environments. Recently, methods have been developed that facilitate implementation of such models. For example, dynamic programming approaches (e.g., Rust 1994) have enabled the representation of consumers' forward looking decision making, and the empirical industrial organizational literature (e.g., Berry 1994; Reiss and Wolak 2002) has produced joint models of supply and demand in which estimable aggregate relations are derived from assumptions of the micro behavior of agents.

At the same time, the strong identifying - mostly parametric - assumptions prove to be the weakness of structural models as well. "We know for the onset in an enterprise like this that what will emerge -at best- is a workable approximation that is useful in answering a limited set of questions." (Lucas 1987). Reduced-form models are often simpler, require less and much weaker assumptions, and allow for more flexible semi-parametric and non-parametric estimation methods. In contrast, many structural models are only parametrically identified (Rust 1994), and cannot be estimated using fully non-parametric methods. Economic theory often has little to say about the functional form, which is then chosen for reasons of analytical tractability. Therefore reduced-form methods are particularly useful in exploratory analyses and specification testing, i.e. in formulating 
theory based on empirical data, and in empirically investigating the validity of structural model assumptions and predictions, and fit well in the empirical research tradition in marketing.

Another potential drawback of structural models is that if "too much" structure is imposed then the models may be less useful for certain decision-making purposes. Consider for example a situation where we estimate demand parameters under the assumption that market data are the pricing outcomes of firms' profit maximizing decisions with firms' interactions following a specific equilibrium concept (e.g., Nash-Bertrand pricing). In this case, we cannot use the demand parameters to come up with "improved" pricing decisions for a firm under that same equilibrium assumption (i.e., Nash-Bertrand), as those parameters have themselves been obtained by imposing “optimal" behavior of firms (see for a related discussion Shugan 2004). Nevertheless, a structural model whose parameters are estimated under one equilibrium assumption (in this case, NashBertrand pricing behavior), can still be used to predict pricing behavior under a variety of alternative equilibria (Stackelberg leader-follower, collusion, etc.) to assess the extent to which firms may be better or worse off under those different interaction regimes. Or a structural model derived under the assumption of a specific information-set available to the agents can be used to simulate counterfactuals with different information sets. Thus, while in the normative approach one seeks to prescribe optimal decisions for firms based on the information available to the analyst, in the structural approach one seeks to identify the constraints in the optimizing behavior of the agents, related for example to bounded rationality, in order to suggest measures to alleviate those constraints (see Reiss and Wolak 2002).

Models often simultaneously exhibit structural and reduced form components, since theory rarely is sufficiently detailed to completely specify a structural model. Therefore, we believe that each model on the structural-reduced-form-continuum should be judged on its merits -plausibility, interpretability, fit, and predictive validity- for the purpose for which it is formulated. Much of the 
distinction between structural and reduced form models that currently prevails in our literature imposes artificial boundaries between models, which may well prove to be counterproductive in furthering knowledge in our field. With this as a starting point, we proceed with our review and evaluation of structural modeling in marketing.

\section{Static Structural Demand Models}

As noted previously, we regard model specifications that are derived from optimizing behavior of agents as structural models. On the demand side, the typical assumption made is that of utility maximizing consumers. ${ }^{2}$ Static demand models are models in which the consumer problem (both utility and the budget constraint) only involves contemporaneous variables. A rich applied demand literature (c.f., Deaton and Muelbauer 1980) has derived demand models from a variety of different utility functional forms. In marketing applications, the familiar logit/probit models of choice are derived from a linear utility specification, where the first recognition that the logit model has a structural interpretation came from McFadden (1974). More recently, models of quantity and multiple-discreteness have been developed from more flexible utility structures (Hanemann 1984; Chiang 1991; Chintagunta 1993, Kim, Allenby and Rossi 2002; and Dube 2004)..

Interest in static demand models has been revived in the empirical I/O literature as models of aggregate demand are derived by aggregating up structural demand models at the individual level (Berry 1994; Berry, Levinsohn and Pakes 1995; Nevo 2000). Much of this literature has focused on policy evaluation, since without a rigorous utility specification, it is impossible to make welfare calculations needed for policy analysis (e.g., Chintagunta, Dubé and Singh 2003). Given the need for an underlying utility formulation, this stream of research has spurred interest in formulating

\footnotetext{
${ }^{2}$ Consumer choices based on alternative decision rules have also been incorporated into demand models - for a recent study see Gilbride and Allenby (2004), for a structural model that includes consideration see Mehta, Rajiv and Srinivasan (2003).
} 
structural demand models at the individual level with adequate functional and parametric representations of heterogeneity. The problem of how aggregate demand can be represented from assumptions on individual demand functions has received much interest in economics (see Stoker 1993). Many of the earlier aggregation approaches were based on the representative consumer assumption (Lewbel 1989), which provides a post-hoc motivation of aggregate demand from a convenient decomposition in customer level demand functions (Stoker 1993). By contrast, recent approaches, based on Berry, Levinsohn and Pakes (1995) explicitly assume an individual level choice model that is derived from utility maximization to underlie the aggregate data. Individuals are assumed to be heterogeneous, with this heterogeneity being explicitly accounted for in the model. Aggregate demand is obtained by integrating individual choices over the distribution of heterogeneity. The marketing literature has contributed significantly to the literature on static demand models by pioneering methods than incorporating both observed and unobserved sources of heterogeneity. Indeed, many of these models are now routinely used to obtain aggregate demand specifications (Allenby and Rossi 1999; Wedel and Kamakura 2000).

\section{Dynamic Structural Demand Models}

If demand depends only upon contemporaneous factors, then structural demand models can be obtained from static utility maximizing behavior. However, consumer choice behavior may exhibit dynamics for several reasons. First, there may be "true" state dependence, that is, choices made in previous periods may causally affect a consumer's current utility, or habit-persistence, in which there is over-time dependence of the random component of utility consumers derive from products (Heckman 1981). Second, there may be choice dynamics due to consumers' forward-looking behavior (Krishna 1992). Forward-looking behavior involves decision-makers taking into account the impact of their current actions on the future stream of utilities (or, profits, if the decision-maker 
is a firm). Thus, forward-looking consumers, for example, maximize the stream of expected utilities over a planning horizon, rather than their immediate utility. As an example, current choices may depend on their information value and their impact on future utilities like in strategic consumer trial or sampling behavior (e.g., Eckstein, Horsky and Raban 1988). Third, there may be dynamic responses to exogenous variables. These dynamic responses could be backward-looking or forwardlooking (such as forming forward-looking price expectations).

State dependence and reference price effects are two important substantive domains that are suited to illustrate some of the advantages of the structural approach to choice or demand dynamics over reduced-form approaches. In the case of state dependence, structural approaches have attempted to explain the behavioral source of state dependence as learning (e.g., Erdem 1998), inertia or variety seeking (e.g., Roy, Chintagunta and Haldar 1996) or switching costs (e.g., Moshkin and Shachar 2002). By contrast, a reduced-form model may approximate such dynamic behavior by including lagged choice variables such as a last purchase dummy, exponentially smoothed weighted average of past purchases, and so on, without explaining why current choices depend on past choices. However, knowing the behavioral sources of state dependence may be important in understanding consumer behavior and different behavioral mechanisms may have different managerial and consumer welfare implications.

A second substantive area to highlight the developments of structural modeling in marketing is the literature on (internal) reference prices, which have been operationalized amongst others as a weighted average of past prices (Winer 1986). Whereas earlier reduced-form models of reference prices studied the impact of reference prices on consumer utilities and choices by including lagged price variables without explicitly explaining why past prices should matter (Kalyanaram and Winer 1995), structural approaches explain the mechanisms behind the reference price effects. For example, reference price effects may be observed if consumers may have forward-looking 
expectations about future prices and promotions and may alter their purchase timing, brand choice and quantity decisions accordingly. Alternatively, consumers may be uncertain about product quality and consider price as a signal of quality.

Forward-looking dynamic structural demand models have three common features ${ }^{3}:$ 1) time and uncertainty are explicitly treated, 2) agents have well-defined objective functions and make their decisions sequentially based on the current information available, their beliefs about nature, and in the case of dynamic models of competition, their beliefs about the strategies of other players, and 3) agents maximize a multi-period objective function, that is, they take the impact of their current choices on future expected utilities into consideration when making current decisions. Thus they are forward-looking, rather than being myopic. We focus on discrete decision-processes involving forward-looking behavior

A significant body of literature in marketing and economics focuses on how consumer learning about brand attributes affects choice behavior, using a dynamic programming approach. Most of the work in question focuses on frequently purchased packaged experience goods. Studies by Eckstein et al. (1988), Erdem and Keane (1996), Anand and Shachar (2002), Ching (2002), Ackerberg (2003), and Crawford and Shum (2003) address quality uncertainty, assuming consumers to be forward-looking, taking into account how the value of information obtained through a trial purchase affects the expected future utility stream. The trade-off involved in this behavior is that sampling different brands for their information value increases the stream of expected utilities, but one may acquire a brand that does not match as well with one's tastes, which decreases immediate utility. In a few of these studies advertising is modeled as a source of quality information. Erdem and

\footnotetext{
${ }^{3}$ These three features exist for forward-looking dynamic structural models of market interactions (e.g., forward-looking structural dynamic models of competition) as well. Given the availability of excellent review papers on the solution and the estimation of dynamic structural models, we do not review such technical issues in this paper. Interested readers can refer to Amman and Rust (1995), Rust (1994) and Pakes (1994) for detailed information on this topic. For more very recent developments such as two-stage methods of estimation, please refer to Pakes, Ostrovsky and Berry (2003) and Bajari, Benkard and Levin (2004). See Doraszelski and Judd (2004) for a discrete and continuous time discussion.
} 
Keane (1996) model the direct informative role of advertising on quality expectations (advertising content provides direct quality information); Ackerberg (2003) models the indirect informative role (signaling) of advertising on consumer quality expectations (advertising frequency signals quality), as well as advertising's direct impact on consumer utility (prestige or persuasive effects of advertising). These models shed light on the relative importance of different advertising effects.

Another area where structural modeling has been applied succesfully in marketing has been the formation of consideration sets. Mehta, Rajiv and Srinivasan (2003) examine the tradeoff of more intense search, which might yield a utility maximizing brand, and higher associated search costs, which may lead to consumers' limiting information search, under quality uncertainty. Their model explains one mechanism why store displays may affect consumer utility by positing that displays reduce consumer search costs. Thus, displays may increase consumer utility not because of an intrinsic utility of a display to a consumer but because displays reduce consumer search costs and increase the probability of a brand being considered. Learning models have also recently been extended to account for forgetting behavior of myopic consumers (see Mehta et al. 2004) where the rate of forgetting depends upon the duration from the last signal received.

A number of studies have considered models of consumer-decision making under uncertainty about future prices, where prices may fluctuate around a mean (mainly due to retailers' price discrimination strategies), as is the case in frequently purchased packaged product categories. Researchers have proposed models where consumer price expectations affect purchase timing, brand choice and quantity decisions. Gönül and Srinivasan (1996) model the impact of coupon availability expectations on purchase incidence. Erdem, Imai and Keane (2003), Hendel and Nevo (2002), Sun, Neslin, Srinivasan (2003) and Sun (2005), estimate dynamic structural models on scanner panel data for frequently purchased consumer goods to examine consumer forward looking price expectations and their impact on purchase timing, brand and quantity choice decisions. In 
these models, the main tradeoff is getting a better price in the future versus the disutility associated with stocking out. More recently researchers have also looked at non-storable product categories such as rounds of golf (Hartmann 2004). The main finding of these studies is that the price (or other marketing mix) elasticities obtained from incorrectly specified reduced form models are biased.

Price and quality uncertainty, and consumer price and quality expectations have been modeled in the context of high-tech durables goods as well. A key feature of high-tech durables markets is the tendency for (mean) prices to fall quickly over time, creating an incentive to delay purchases. Melnikov (2000) models consumer behavior in this context using data from the computer printer market. Song and Chintagunta (2003) analyze the impact of price expectations on the diffusion patterns of new high-technology products using aggregate data. Erdem, Keane and Strebel (2003) model both learning about quality and the expectations about future prices in a unified framework of consumer information search and choice of technology in the PC market. In this setting, both learning and expectations of declining prices can generate incentives to delay purchase of a durable whereas delaying involves forgone utility of consumption. Thus, the main trade-off that consumers face in high-tech durable goods markets is between a lower price or better product and/or a lower level of uncertainty associated with their decisions on the one hand versus the forgone utility of consumption associated with delayed purchase on the other hand. The paper finds that demand elasticities that account for how a price change today alters expectations of future price changes - exceed estimates that ignore the expectations effect by roughly $50 \%$. The modeling approach allows one to evaluate the impact of changes in the cost and accuracy of information on consumer information search and technology choice.

Overall, the empirical findings in the stream of research on forward-looking dynamic structural demand models suggest that

1) Consumers are forward-looking at least for certain categories of products; 
2) The extent of biases in parameter estimates associated with assuming myopic consumers when they are in fact forward-looking varies across contexts.

3) The estimated models fit both in-sample and out-of-sample data well. Thus, the explanatory power and predictive power are often high;

4) The models tend to have both structural and reduced form components;

5) The underlying structural assumptions (e.g., forward looking behavior, Bayesian updating) are often not tested or further investigated;

6) Increasingly, there is a need to use multiple data sources (e.g. survey data on expectations) to relax and test some of the commonly made assumptions (e.g., rational expectations), as well as to enhance the behavioral richness and interpretation of these models.

\section{Structural Models of Demand and Firm Behavior}

So far our focus has been on understanding the demand side - what are the key drivers of consumer behavior and how do we incorporate those drivers into econometric models we can take to the data? Unless experimentally determined, variables that influence demand such as prices and advertising levels are set by firms that maximize their objective functions (typically, profits) while competing in the marketplace. Structural models of demand that also account for firm behavior assume that observed market data are equilibrium outcomes for rival firms given a demand specification. There are several reasons why marketing researchers may be interested in characterizing the "supply" side - to resolve potential endogeneity biases, to measure and test the nature of interactions among firms, to test theories of competition and for policy analysis by simulating behavior under a variety of market environments.

As we discuss below, addressing some of the above issues requires imposing the equilibrium conditions implied by the supply side model while estimating the parameters of the demand 
function. At the same time, there are situations in which the equilibrium conditions are used primarily to contrast predictions regarding firm behavior under alternative behavioral regimes after the parameters for the demand function have been estimated. A feature of the simultaneous estimation of demand and firms' behavior (when equilibrium conditions are imposed in the estimation), is that the latter equations also depend upon the firms' cost functions. In particular, when considering pricing decisions, the pricing equations depend upon marginal cost and when considering advertising decisions, the equations depend upon the parameters of the advertising cost functions. In situations where these costs are observed, they can be used in the estimation as data. Typically however, these cost functions are unknown and are therefore operationalized as functions of observed factors of production (for production costs) or actual advertising levels expressed in metrics such as GRPs (for advertising costs). The parameters characterizing these functions are then estimated from the data along with the demand function parameters. Hence cost estimates are useful by-products of the estimation of structural models of demand and firm behavior.

As with the demand side, firms can make decisions to maximize current period profits or profits over a longer term horizon depending upon whether or not current period actions have consequences for future payoffs. A majority of applications thus far have been limited to the static domain, largely due to the tractability of solving the firm's problem and / or estimating the parameters that characterize demand and firm behavior. Recent advances (see for example, Pakes et. al. 2003, Bajari et al. 2004 and Pesendorfer and Schmidt-Dengler 2003) in the estimation of dynamic oligopoly games has somewhat ameliorated the situation. Nevertheless dynamic firm models have a ways to go before widespread application.

\subsection{Resolving Potential Endogeneity Biases}

Firms set their levels of marketing activities to maximize an objective function such as profits. Profits are a function of demand. The demand function depends on variables such as prices, 
advertising, distribution, etc as well as on other shocks to demand from the environment in which the firm operates. While firms observe all these factors, researchers may have access to information only on a subset of these variables (e.g., only price). Further, researchers do not observe the other demand shocks. For the researcher then, this set of unobserved variables constitutes the error term of the demand function. To the extent that firms observe all the demand drivers, they will take them into account while making decisions on the levels of their marketing activities. Consequently, observed levels of marketing variables (e.g., price) will depend upon the unobserved factors that are part of the error term in the demand equation. This correlation between observed and unobserved variables in the demand equation, if ignored by the researcher, will result in a bias in the estimated effect of the observed variable (e.g., price) on the demand. This bias has been referred to as the “endogeneity bias."

One approach to accounting for the endogeneity bias is to use instrumental variables to "proxy" for the endogenous variables. Instruments are, loosely speaking, variables that are exogenous, uncorrelated with the troublesome unobserved demand driver, but correlated with the observed endogenous variable. It is important to realize that in most applications, one must resort to theoretical considerations to determine if a given variable is a valid instrument. All too often, variables are picked to be instruments without much formal justification. The IV approach is popular in the economics literature and has seen several applications in the marketing literature as well. The principal advantage of this approach is that it allows the researcher to remain agnostic about the nature of firm behavior that generates the correlation between the observed and unobserved factors. Further, the estimates are consistent as long as the endogenous variables are properly instrumented for. The key challenge however, is to identify the appropriate instruments that are correlated with the endogenous variables but are uncorrelated with the error term. Another potential drawback is that the estimates are inefficient. 
The endogeneity bias can also be resolved if one imposes the relationship between the observed and unobserved variables while estimating the demand parameters. The econometric model in this case will consist of a system of equations that will include the demand function as well as the firms' optimizing equations for the observed marketing variables of interest. By explicitly accounting for the manner in which the correlation between the observed and unobserved variables in the demand function is generated, the supply side helps us to resolve the endogeneity issue. It is important to note that the key focus here is still on obtaining estimates for demand function parameters. The estimates in this case are efficient. However, there is the possibility of obtaining inconsistent estimates for the demand parameters if one imposes the incorrect supply-side model in the estimation.

It is important to note that one can avoid the endogeneity issue entirely if the demand drivers controlled by the firm (e.g., price) are experimentally determined such as in certain direct marketing contexts. If researchers can promote the use of experimentation and randomization by firms from which they obtain their data, then the need to address the endogeneity issue is alleviated. However, since a majority of data analyzed is not of the experimental variety, the methods described above to resolve the bias are still very relevant.

\subsection{Measuring and Testing the Nature of Interactions among Firms}

Often one is interested in identifying the nature of competitive interactions among firms in a market. For example, researchers and policy makers may be interested in determining whether firms in a market are behaving collusively with one another or whether the nature of competition is fierce. Further, as interactions can vary across marketing instruments, one may also be interested in studying interactions across different marketing variables. The structural approach that jointly estimates demand function parameters with the equations governing firm behavior provides a natural framework for accomplishing this task. Given a demand model, we can write out the 
equations for the marketing mix variables that correspond to different behavioral regimes (BertrandNash, Stackelberg leader-follower, collusion, etc.). One can then test, using market data, which of the behavioral assumptions is most consistent with the available data. An early empirical example of such research is the study by Gasmi, Laffont and Vuong (1992). Here the authors investigate the nature of pricing and advertising interactions among firms in the U.S. soft drinks market. Several studies in the marketing literature have attempted to uncover the nature of competitive interactions among brands and firms. Kadiyali et al. (1996) look at product line pricing by multi-product firms and finds that firms position their smaller brands as followers to the larger brands of rival firms. Vilcassim et al. (1999) study pricing and advertising interactions among firms competing in a health and beauty aids category and find that while competition is muted in pricing, it is fierce in advertising. Sudhir (2001) finds that nature of pricing varies across segments in the U.S. automobile market. In particular the larger car and luxury segments show evidence of more collusive pricing, the small car segment is lot more competitive in nature.

\subsection{Testing Theories of Competition}

The marketing and economics literatures have proposed several theories that make predictions about the extent of competitive interactions among firms. To the extent that structural models enable us to measure the nature of inter-firm competition, they should also enable us to test whether the proposed theories are consistent with data. Here we provide two recent illustrations from the marketing literature. In a recent paper, Besanko, Dube and Gupta (2003) test the predictions regarding targeted couponing by manufacturers proposed by Shaffer and Zhang (1995). In particular, Shaffer and Zhang (1995) show in a theoretical model that targeted couponing leads to a prisoner's dilemma in which all manufacturers issue coupons without profitably increasing their

prices. By contrast, using data from the ketchup category in the Springfield, MO market, and a structural model of demand and pricing, Besanko et al (2003) find that such coupons can increase 
manufacturer profitability. The key to this finding is that Shaffer and Zhang (1995) use a demand model in which there is only horizontal differentiation among firms. With such a specification the equilibrium for firms is "all out competition" which leads to the finding that targeted coupons are not profitable for manufacturers. By contrast, the structural demand model in Besanko et al (2003) also allows for vertical differentiation which helps counter the all out competition result. Therefore, by attempting to test a previous theoretical prediction in the literature, Besanko et al (2003) were able to uncover a potential "boundary condition" for that result.

Another recent example of a study on this vein is that by Sudhir, Chintagunta and Kadiyali (2005). Here the authors are interested in testing which of two alternative theories in the repeated games literature is more consistent with market data from the U.S. photographic film market. Green and Porter (1984) predict that competitive intensity will be higher in periods of low demand, while Rotemberg and Saloner (1986) make the opposite prediction. By making the level of competitive interaction among the firms (Kodak and Fuji) a function of demand drivers, Sudhir et al. (2005) find support for the Rotemberg and Saloner (1986) theory for the photographic film market. While the study has some features of a reduced-form model embedded within a structural formulation, the basic idea of testing theories of competition using structural models is likely to be an important area of application of such models in the future.

\subsection{Policy Analysis and Simulating Firm Behavior}

This is perhaps the one area in which structural models have seen a lot of application. In the economics literature structural models have been applied extensively to merger simulations. By contrast, the marketing literature has seen applications to pricing (Chintagunta et al. 2003), advertising (Dube, Hitsch and Manchanda 2004) and new product introductions (Horsky and Nelson 1992; Hitsch 2004), etc. As the focus of marketing studies shifts away from reporting 
parameter estimates and elasticities to understanding the substantive implications for behavior, we would expect policy analysis to become an increasingly common feature in these studies.

The basic requirements for simulating the behavior of firms are a) the parameters of the demand model, b) the equations governing firm behavior, i.e., the policies under various behavioral assumptions, and c) data on exogenous variables on the demand and supply side. Supply side exogenous data may or may not include data on costs. If cost data are not available they need to be inferred via joint estimation of demand equations and equilibrium conditions. In this case, policy simulations will correspond to behavioral regimes other than the one imposed in the estimation of model parameters. We briefly discuss a couple of studies in the marketing literature that have carried out such simulations in order to provide a flavor for the types of analyses possible with the structural approach.

Chintagunta et al. (2003) investigate the issue of price discrimination by a retail chain. Here the authors are interested in studying the impact on chain profits and customer welfare when a retail chain (a) sets uniform prices across all stores; (b) assigns the stores to pricing "zones," and sets uniform prices within zones; and (c) sets store-specific price levels. To address this issue it is necessary to simulate prices under the above three behavioral regimes. Prices are a function of the retailer's marginal costs (i.e., wholesale prices) and markups under the different regimes. Since wholesale prices are observed in their data and as markups are purely a function of demand parameters, this is a situation in which it is not necessary to impose the retailer's pricing equations while estimating demand parameters. Rather, Chintagunta et al. (2003) estimate the parameters of store-level demand functions using retail sales data, while accounting for price endogeneity by using wholesale prices as instrumental variables for retail prices, thereby remaining agnostic about the process generating prices. A key benefit of this approach is that the authors then simulate prices under the assumption of zone pricing, which according to managers of the retail chain was the actual 
prevailing price setting mechanism. A comparison of the true retail prices to the simulated prices provides a test of the demand function - a useful by-product of the analysis. After verifying the appropriateness of the demand model, prices are simulated under the alternative chain- and storelevel pricing schemes. The authors find that store-level pricing may be better suited to some categories than others. Hence the results of the analysis provides useful input to retail managers interested in determining prices for stores in the chain.

Marketers spend billions of dollars annually on various forms of advertising by firms competing in the various product-markets. Yet, while there had been a significant amount of interest in advertising policies of firms over the past 30 years, very little progress has been made in the marketing literature in terms of implementable models that predict the type of advertising commonly observed in the market - that of "pulsing." In large part this is due to advertising expenditures influencing both current period as well as future firm payoffs which require the application of dynamic models of demand as well as of firm behavior. Given the complexity of dynamic oligopoly models, researchers have had to use simple advertising demand models to be able to characterize firm behavior. Unfortunately these demand models are typically not consistent with the commonly observed pulsing outcome, thereby reducing their usefulness from an applied perspective. Dube et al. (2004) address the issue of dynamic advertising strategies of rival firms. They begin with a demand model that permits pulsing as an equilibrium outcome. Then, they theoretically characterize the equilibrium advertising levels of firms using the Markov-perfect equilibrium solution concept. Using data from the frozen entrée market, Dube et al. (2004) estimate the parameters of the demand model without imposing the advertising equilibrium conditions. Using the estimated demand parameters, the authors then verify whether the equilibrium in the market is for firms to pulse - a behavior indicated by the actual observed advertising levels. As in the Chintagunta et al. (2003) study above, such an analysis is possible as the authors observe advertising 
costs in the market. Further, they use the estimated parameters to compute the optimal advertising levels for the competing firms. In this case, as with the previous illustration, structural models form the basis of useful managerial input.

\subsection{Other Issues}

Besides the above reasons for being interested in the supply side of the market, it is also possible that there are some situations in which the extra restrictions implied by the equilibrium conditions facilitate identification of the demand parameters. In situations where researchers do not have access to rich demand data, the cross-equation restrictions implied by the demand and supply equations could help in better pinning down demand parameters such as the price coefficient. While this might not be a central reason for incorporating the supply side, it could nevertheless be a benefit in certain situations. The key tradeoff that needs to be recalled here is that imposing the incorrect equilibrium conditions can result in inconsistent estimates of parameters in both demand and supply equations. An extreme case where the presence of the supply side helps in the estimation of the demand parameters is when we do not observe market demand but do observe firms' actions, e.g., prices. For example, Thomadsen (2004) observes prices charged by competing franchisees in the fast-food product market but not the sales of the different outlets. By writing out the demand and pricing equations for the firms and by substituting in the demand function expression into the pricing equation; he obtains a system of equations that relate prices to exogenous variables and model parameters. This is case where the researcher literally substitutes theory for data. The key issue then is whether the model parameters are indeed identified using the data on hand.

To summarize, researchers may be interested in characterizing firm behavior for a variety of reasons. Some of these are to obtain appropriate demand estimates, others are to better describe markets and a third category is to provide inputs to managerial decision-making. Further, it is important to keep in mind that imposing one form of market equilibrium while estimating model 
parameters does not preclude firms from exploring the profit consequences of alternative behavioral regimes. Of course, not having to impose equilibrium behavior in the estimation of demand parameters will help managers and researchers to explore the consequences of a larger set of behaviors and in some cases (when costs are observed) to also test the validity of demand models.

\section{Discussion, Current and Future Research}

We have emphasized that the value of a structural approach is the ability to make predictions of the effects of policy/strategy changes. We view such a change as a change in the stochastic process governing the marketing mix variables. This is achieved at a cost, namely that assumptions must be made about the form of the utility or objective function, the form of budget or other constraints, the distribution of unobservable components, and, possibly, the nature of equilibrium in a given market. Most structural models make rather strong parametric assumptions regarding these various components. Typically, little specification testing is done on structural models due to the difficulty of estimation of the models. In addition, it may be difficult to derive the implications for the joint distribution of observable quantities for a particular structural model. Non-parametric or semi-parametric methods are typically not used with structural models with the notable exception of some models in the auctions literature. In addition, applications of structural models often contain a reduced-form component. That is to say, theory is seldom sufficiently detailed to enable a complete specification of the model, and there will be aspects of the model which are not derived from a strict theory of optimizing behavior. An example is the inclusion of a lagged purchase indicator variable in forward looking models. That provides better fit to the data in most cases, but, is a reduced form representation that may conflict with the core structural behavioral assumption, since it assumes that consumers anticipate the effect of their future choice outcomes on subsequent utility formation. And structural models are only devoid of the Lucas' critique to the extent that their assumed 
economic primitives are invariant to policy changes (for example, in aggregated logit models of demand price coefficients are often assumed to be constant, and in models that incorporate forward looking behavior prices are assumed exogenous). We expect that improvements in computation will allow researchers to fit more flexible structural models and to perform more sensitivity analysis. This will allow us to get a better idea of what is identified from the data and what is identified only via parametric restrictions.

While providing a particularly powerful framework, these structural approaches are also not without limitations, see for example studies by Anderson and Vilcassim (2001), Yang, Chen and Allenby (2003) and Bajari and Benkard (2003). The disaggregate or aggregate logit models with an outside good commonly used, ignore continuous aspects of demand (cf. Reiss and Wolak 2002; Hanemann 1984), need to involve assumptions on the size of the market (see Berry et al. 1995; Reiss and Wolak 2002), and constrain the cross-elasticities rendering their estimates small which has major implications for pricing strategy (see Anderson and Vilcassim 2001). If these strong functional restrictions are inadequate, this may lead to incorrect inferences on market power or cost structures. In addition, many of the estimation approaches use more or less ad-hoc (simulated) methods-ofmoments estimators and rely on the use of instrumental variables to solve for the problem of "endogeneity". These instruments are variables that mimic the endogeneous regressor but are uncorrelated with the error, and are preferably derived from theory, as explained above. However, this method suffers from at least two problems: (1) there may not be theory to guide the selection of the instruments, or the instruments may otherwise be costly to obtain, (2) the quality of the inferential procedures relies on the extent to which these instruments are valid. In many cases the instruments are weak, which leads to serious problems with the asymptotic theory underlying inference (Bowden and Turkington 1984; Bound, Jaeger and Baker 1995; Staiger and Stock 1997; Hahn and Hausman 2002). 
Current studies search for solutions of many of these problems. Nair, Dube and Chintagunta (2003) develop an approach that allows for estimating individual discrete/continuous demand functions from aggregate data Hogan and Rigobon (2003), Ebbes et al. (2004), and Manchanda, Rossi and Chintagunta (2004) develop methods that circumvent the search for observable instruments, Yang, Chen and Allenby (2003) develop approaches to estimate individual level demand/supply system through full Bayesian, or maximum likelihood inference. Work to estimate aggregated demand functions and supply systems within those more rigorous frameworks for statistical inference and work on ways to significantly simplify the estimation is also on its way.

A more important caveat is the following, already briefly touched upon in the introduction. Many structural models have been developed by economists or adapted from the economics literature. There is an important difference in the orientation of the economics and marketing literatures. Economics is usually viewed as a positive science that seeks to explain observed behavior as the result of optimizing behavior and, possibly, a definition of market equilibrium. Marketing, on the other hand, is a normative field that seeks to provide guidance to firms to improve as measure by some performance metric. Thus, structural modeling approaches must be used with some care. If we assume that firms are optimally deploying their marketing resources, then we don't have much to say in terms of prescriptive advice for improvement. This may seem to be a damning critique of structural approaches but it is important to remember that this depends on assumptions about firm behavior and the information available to them. For example, if we estimate a structural demand model, then we can use the estimates to make policy/strategy recommendations. However, if we also impose supply side restrictions in estimating the demand parameters, then we have assumed that firms are optimally allocating marketing resources conditional on our assumptions regarding the nature of interactions among firms and the information available to them. We do not always have to assume full optimality, in the sense that we 
might assume that firms are optimally allocating a subset of their resources or information rather than the full set. For example, we can assume that firms are pricing optimally given the positioning of products without assuming some sort of equilibrium positioning of products and number of products. This will allow us to make normative conclusions regarding positioning. The definition of optimality requires a specification of an information set. For example, it is typical in the economics literature to assume that firms know aggregate demand perfectly. On the demand side, we often assume that consumers have perfect information about the marketing environment they face in making purchase decisions. Structural models which do not make these extreme assumptions regarding information and optimality -including bounded rationality, limited information and optimization errors, are an important direction for future research. As the marketing environment becomes more information intensive, we can consider and evaluate the possibility of profit opportunities with respect to a richer information set, using parameters estimated from a structural model assuming optimality with respect to a coarser information set. There is no inconsistency here between positive and normative objectives.

We expect policy simulations from structural models to be increasingly used in situations where we need to evaluate the consequences of marketing actions that might be difficult to evaluate otherwise. Consider for example, channel related decisions. A firm selling several product lines through retail and internet channels might consider moving one of its lines from the retail to the internet channel. In this case we may be able to evaluate the effects of the channel switch on the firm's profits, rival profits and customer welfare by first estimating a demand and pricing model under the current channel structure and then simulating the new prices and demand that will prevail 
in the market due to the channel switch. ${ }^{4}$ Evaluating such multi-channel strategies is only one possible application of structural models to evaluating the consequences of strategic shifts by firms.

We expect that the future development of structural models in marketing will focus on the interface between economics and psychology. There are two reasons for this. First, structural models are focused on explaining behavioral processes that lead to market outcomes (which improves prediction in dynamic environments and facilitates policy evaluation). The need for richer theories of consumer behavior and processes is expected to stimulate more interaction between economics, marketing and psychology. There is already some early work suggesting ways to integrate alternative behavioral mechanisms into structural models (e.g., El-Gamal and Grether 1995). Second, there is a growing need to test alternative assumptions regarding behavioral processes. For example, there is a large literature on Bayesian updating and deviations from Bayesian expectation formation processes. Similarly, work on hyperbolic discounting may help us to capture consumer forward-looking expectations better and alter some of the assumptions often made in regard to how consumers discount future events. Behavioral economics and decision-science literatures have discussed behavioral processes such as reference dependence, focusing and bracketing effects, present-biased preferences, and biases in judgment, quasi-Bayesian behavior and the like. Integrating some of these concepts formally into dynamic structural models is both challenging and rewarding.

\footnotetext{
${ }^{4}$ This assumes of course, that we can write out the demand and pricing equations under the existing and new channel structures. Structural models in marketing have typically not accounted for complex channel arrangements that may exist in certain product-markets. Addressing this issue might in of itself be a fruitful avenue of research.
} 


\section{References}

Ackerberg, D. 2003. Advertising, learning, and consumer choice in experience good markets: A structural empirical examination. International Economic Review 44 1007-1040.

Allenby, G., P. Rossi 1999. Marketing models of heterogeneity. Journal of Econometrics 89 57-78.

Amman, H., J. Rust 1995. Numerical dynamic programming. H. Amman, D. Kendrick, J. Rust, eds. Handbook of Computational Economics. Amsterdam: North Holland vol 1.

Anand, B, R. Shachar 2002. Risk aversion and apparently persuasive advertising. Working paper series 02-099, Harvard Business School.

Anderson, E., N. J. Vilcassim. 2001. Structural demand models for retail category pricing. Working paper, University of Chicago, Chicago, IL.

Bajari, P., C. L. Benkard. 2003. Discrete choice models as structural models of demand: Economic implications of common approaches. Working paper, Department of Economics, Stanford University.

Bajari, P., C. L. Benkard, J. Levin. 2004. Estimating dynamic models of imperfect competiton. Working paper, Department of Economics, Duke University.

Berry, S. 1994. Estimating Discrete-Choice Models of Product Differentiation. RAND Journal of Economics, 25 (2), 242-262.

Berry, S., J. Levinsohn, A. Pakes. 1995. Automobile prices in market equilibrium. Econometrica 63 841-890.

Besanko, D., J. Dubé, S. Gupta. 2003. Competitive price discrimination strategies in a vertical channel using aggregate retail data. Management Science. 49 (9) 1121-1138.

Bound, J. D.A. Jaeger, R.M. Baker. 1995. Problems with instrumental variables estimation when the correlation between the instrument and the endogeneous explanatory variable is weak. Journal of the American Statistical Association. 90 443-450.

Bowden, R.J., D.A. Turkington. 1984. Instrumental Variables, Cambridge University Press, New York.

Chiang, J. 1991. A simultaneous approach to the whether, what, and how much to buy questions. Marketing Science 10(Fall) 297-315.

Ching, A. 2002. Consumer learning and heterogeneity: dynamics of demand for prescription drugs after patent expiration. Working paper, Ohio State University.

Chintagunta, P. K. 1993. Investigating purchase incidence, brand choice and purchase quantity decisions of households. Marketing Science 12 (Spring) 184-208.

Chintagunta, P. K., J. Dubé, V. Singh. 2003. Balancing profitability and customer welfare in a supermarket chain. Quantitative Marketing and Economics 1 (1) 111-147.

Chintagunta, P. K., V. Kadyali, N. Vilcassim. 2004. Structural models of competition: A marketing strategy perspective. C. Moorman, D. Lehmann, eds. Assessing Marketing Startegy Performance. The Marketing Science Institute, Cambridge, MA.

Crawford, G. S., M. Shum, 2003. Uncertainty and learning in pharmaceutical demand: Anti-ulcer drugs. Working paper, University of Arizona.

Deaton, A., J. Muelbauer. 1980. An almost ideal demand system. The American Economic Review 70 (3) 312-326.

Doraszelski, U. and K. Judd 2004. Avoiding the curse of dimensionality in Dynamic Stochastic games, working paper, Department of Economics, Harvard University

Dubé, J. 2004. Multiple discreteness and product differentiation: Demand for carbonated soft drinks. Marketing Science 23 66-81.

Dube, J., G. Hitsch. P. Manchanda. 2004. An empirical model of advertising dynamics. Working paper, The University of Chicago.

Dubé, J., P. Chintagunta, A. Petrin, B. Bronnenberg, R. Goettler, P.B. Seetharaman, K. Sudhir, R. Thomadsen, Y. Zhao. 2002. Structural applications of the discrete choice model. Marketing Letters 13 (3) 207.

Ebbes, P., T.G.M. Steerneman, M. Wedel, U. Bockenholt. 2004. New evidence for the effect of education on income: Solving endogeneity with latent instrumental variables. Working paper, University of Michigan Business School.

Eckstein, Z., D. Horsky, Y. Raban. 1988. An empirical dynamic model of brand choice. Working paper 88, University of Rochester.

El-Gamal, M. A., D. M. Grether. 1995. Are people bayesian? Uncovering behavioral strategies. Journal of the 
American Statistical Association 901137-1145.

Erdem, T. 1998. An empirical analysis of umbrella branding. Journal of Marketing Research 35(3) 339-351.

Erdem, T., M. P. Keane. 1996. Decision-making under uncertainty: capturing dynamic brand choice processes in turbulent consumer goods markets. Marketing Science 15 1-20.

Erdem, T., S. Imai, M. P. Keane. 2003. Brand and quantity choice dynamics under price uncertainty. Quantitative Marketing and Economics 1 5-64.

Erdem, T., M. Keane. J. Strebel. 2003. Learning about computers: An analysis of information search and technology choice. Forthcoming in Quantitative marketing and Economics.

Erdem, T., K. Srinivasan, W. Amaldoss, P. Bajari, H. Che, T. Ho, W. Hutchinson, M. Katz, M. Keane, B. Meyer and P. Reiss. 2005 “Theory Driven Choice Models.” Working Paper, UC Berkeley.

Gasmi, F., J. Laffont, Q. Vuong. 1992. Econometric analysis of collusive behavior in a soft-drink market. Journal of Economics and Management Strategy 1(2) 277-311.

Gilbride, T., G. M. Allenby. 2004. A choice model with conjunctive, disjunctive, and compensatory screening rules. Marketing Science, 23 (3) 391-406.

Gönül, F., K. Srinivasan. 1996. Estimating the impact of consumer expectations of coupons on purchase behavior: A dynamic structural model. Marketing Science 15 262-279.

Green, E., R. Porter. 1984. Noncooperative collusion under imperfect price information. Econometrica 5287 100.

Haavelmo, T. 1944. The probability approach in econometrics. Econometrika Supplement 12 1-115.

Hahn J., J. Hausman. 2002. A new specification test for instrumental variables. Econometrica 70 163- 189.

Hanemann, W. M. 1984. Discrete continuous models of consumer demand. Econometrica 52 541-561.

Heckman, J. 1981. Heterogeneity and State Dependence. S. Rosen, ed. Studies in Labor Markets. University of Chicago Press, Chicago, IL.

Hendel, I., A. Nevo. 2002. Measuring the implications of sales and consumer stockpiling behavior. Working paper, UC Berkeley, CA.

Hitsch, G. 2004. An empirical model of optimal dynamic product launch and exit under demand uncertainty. Working paper, University of Chicago, Chicago, IL.

Hogan, V. and R. Rigobon.2003. using Unobserved Supply Shocks to Estimate the Returns to Education. NBER Working Paper 9145, MIT.

Horsky, D., P. Nelson. 1992. New brand positioning and pricing in an oligopolistic market. Marketing Science 11 (2) 133-153.

Kadiyali, V., N. Vilcassim, P. Chintagunta. 1996. Empirical analysis of competitive product line pricing decisions: Lead, follow or move together? Journal of Business 9 (4) 459-487.

Kadiyali, V., K. Sudhir, V. R. Rao. 2000. Structural analysis of competitive behavior. International Journal of Research in Marketing 18 (1-2) 161-185.

Kalyanaram, G, F. S. Winer. 1995. Empirical generalizations from reference price and asymmetric price response research. Marketing Science 14 (part 2 of 2 in issue 3) G161-G169.

Kim, J., G. M. Allenby, P. E. Rossi. 2002. Modeling consumer demand for variety. Marketing Science 21 (3) $229-251$

Krishna, A. 1992. The normative impact of consumer price expectations for multiple brands on consumer purchase behavior. Marketing Science 11 (Summer) 266-286.

Lewbel, A. 1989. Exact aggregation and a representative consumer. Econometrica 104 (3) 621-633.

Lucas, R. E. 1976. Econometric policy evaluation: A critique. K. Brunner, A. H. Meltzer, eds. The Phillips Curve and Labor Markets, Carnegie-Rochester Conference Series on Public Policy 1 19-46. Reprinted in R.E. Lucas, Jr. Studies in Modern Business Cycle Theory. MIT Press, Cambridge, MA.

Lucas, R. E. 1987. Models of business cycles. Blackwell Publishing, Oxford, U.K.

Manchanda, P., P. E. Rossi, P. K. Chintagunta. 2004. Response modeling with non-random marketing mix variables. Journal of Marketing Research forthcoming.

McFadden, D. 1974. Conditional logit analysis of qualitative choice behavior. P. Zarembla, ed. Frontiers of Econometrics. Academic Press, New York, NY

Mehta, N., S. Rajiv, K. Srinivasan. 2003. Price uncertainty and consumer search: A structural model of consideration set formation. Marketing Science 22 (1) 58-84. 
Mehta N, S. Rajiv and K. Srinivasan 2004. Role of Forgetting in Memory-based Choice Decisions. Quantitative Marketing and Economics, 2 (2), 107-140.

Melnikov, O. 2000. Demand for differentiated durable products: The case of the U.S. computer printer market. Working paper, Yale University.

Moshkin, N., R. Schachar. 2002. The asymmetric information model of state dependence. Marketing Science 21 (4) $435-454$.

Nair, H., J-P Dube, P.K. Chintagunta. 2003. Accounting for primary and secondary demand effects with aggregate data. Marketing Science forthcoming.

Nevo, A. 2000. Mergers with differentiated products: The case of ready-to-eat cereal industry. RAND Journal of Ecomomic, 31 (3) 395-421.

Pakes, A. 1994. Dynamic Structural Models, problems and prospects: mixed continuous discrete controls and market interactions. Christopher A. Sims, ed. Advances in Econometrics Sixth World Congress. Cambridge University Press, Cambridge, U.K.

Pakes, A., M. Ostrovsky, S. Berry. 2003. Computationally simple estimators for entry games. Working paper, Department of Economics, Harvard University.

Pesendorfer, M., P. Schmidt-Dengler. 2004. Identification and estimation of dynamic games. Working paper, University of London - London School of Economics \& Political Science.

Reiss, P. C., F. A. Wolak. 2002. Structural econometric modelling: Rationales and examples from industrial organisation. Handbook of Econometrics forthcoming.

Rotemberg, J., G. Saloner. 1986. A super-game theoretic model of business cycles and price wars during booms. American Economic Review 76 (3) 390-407.

Roy, R., P. K. Chintagunta, S. Haldar. 1996. A framework for analyzing habits, 'hand-of-past' and heterogeneity in dynamic brand choice. Marketing Science 15 (3) 280-299.

Rust, J. 1994. Estimation of dynamic structural models, problems and prospects: discrete decision processes. Christopher A. Sims, ed. Advances in Econometrics Sixth World Congress. Cambridge University Press, Cambridge, U.K.

Shaffer, G., J. Zhang. 1995. Competitive coupon targeting. Marketing Science 144.

Shugan, S. 2004. Editorial: Endogeneity in Marketing Decision Models. Marketing Science 23 (1), 1-3.

Song, I., P. Chintagunta. 2003. A micromodel of new product adoption with heterogeneous and forwardlooking consumers: Application to the digital camera category. Quantitative Marketing and Economics 1 (4) 371-407.

Staiger, D., J. H. Stock. 1997. Instrumental variables regression with weak instruments. Econometrica $65557-$ 586.

Stoker, T. 1993. Empirical approaches to the problem of aggregation over individuals. Journal of Economic Literature 31 (December) 1827-1874.

Sudhir, K. 2001. Competitive pricing behavior in the auto market: A structural analysis. Marketing Science $\mathbf{2 0}$ (1) $42-60$.

Sudhir, K., P. K. Chintagunta, V. Kadiyali. 2005. Time varying competition. Marketing Science forthcoming.

Sun, B 2005. Promotion Effect on Endogeneous Consumption. Marketing Science, 24 (3), forthcoming.

Sun, B., S. Neslin, K. Srinivasan. 2003. Measuring the impact of promotions on brand switching under rational consumer behavior. Journal of Marketing Research 40 (4) 389-405.

Thomadsen, R. 2004. the effects of ownership structure on prices in geographically differentiated industries. Working paper, Columbia University, New York, NY.

Vilcassim, N. J., V. Kadiyali, P. Chintagunta. 1999. Investigating dynamic multifirm interactions in price and advertising. Management Science 45 (4) 499-518.

Wedel, M., W. A. Kamakura. 2000. Market Segmentation: Conceptual and Methodological Foundations. Kluwer, Dordrecht, Netherlands.

Winer, Russell S. (1986), "A Reference Price Model of Brand Choice for Frequently Purchased Products," Journal of Consumer Research, 13 (2), 250-256

Yang, S., Y. Chen, G. Allenby. 2003. Bayesian analysis of simultaneous demand and supply. Quantitative Marketing and Economics 1 251-275. 